narrativo e discursivo, carrega consigo uma carga simbólica que não pode ser ignorada $e$ que precisa ser resgatada para que o ato de escrever e ler adquira sua significação plena.

Angelina Batista

Tese de Doutorado, 1997 Orientador: Prof. Dr. José Carlos de Paula Carvalho Faculdade de Educação/USP

\section{ARTICULAÇÃO PESQUISA/ENSINO NA UNIVERSIDADE BRASILEIRA. $O$ caso do Centro de Ciências Biológicas da Universidade Estadual de Londrina}

Trata-se de uma pesquisa que trabalha com dados quantitativos e qualitativos, buscando verificar o grau de articulação pesquisa/ ensino na universidade e focalizando, através de um Estudo de Caso, a situação específica do Centro de Ciências Biológicas (CCB) da Universidade Estadual de Londrina (UEL). Nesse sentido, busca-se analisar as contribuições da literatura sobre essa articulação (pesquisa/ensino) no Ensino Superior e relacioná-las com as informações obtidas sobre o tema na UEL. Os informantes são professores pesquisadores desse Centro de estudos, chefes de departamento, exalunos que hoje são docentes e que durante a graduação participaram de projetos de pesquisa e ex-diretores de pesquisa da Coordenadoria de Pesquisa e Pós-graduação. Os dados do caso são colhidos em documentos oficiais, depoimentos escritos $e$ entrevistas, valorizando, para análise, as representações que os sujeitos têm sobre suas vivências relativas ao tema abordado. São detectadas as principais estratégias que facilitam e os problemas que dificultam a articulação entre o conhecimento produzido pelas pesquisas e o trabalho do pesquisador enquanto docente em sala de aula. $O$ trabalho aborda também as formas de disseminação do conhecimento novo produzido para além das salas de aula. As contribuições pretendidas são em nível de diagnóstico e autoconhecimento para os professores, para os Departamentos, para o Centro de Estudos e para a Instituição. Concluindo, pela investigação realizada, foi possível constatar que no $\mathrm{CCB}$, junto aos professores pesquisados, a articulação pesquisa/ensino não é mais um mito. Constitui uma realidade que poderá servir de exemplo não só para os seus pares como para toda a Universidade.

Maria Aparecida Vivan de Carvalho Tese de Mestrado, 1996 Orientadora: Profa Dra Neusi Aparecida N. Berbel Faculdade de Educação/UEL 